This is the author's final, peer-reviewed manuscript as accepted for publication. The publisher-formatted version may be available through the publisher's web site or your institution's library.

\title{
Complement, natural antibodies, autoantibodies and tissue injury
}

Sherry D. Fleming and George C. Tsokos

\section{How to cite this manuscript}

If you make reference to this version of the manuscript, use the following information:

Fleming, S. D., \& Tsokos, G. C. (2006). Complement, natural antibodies, autoantibodies and tissue injury. Retrieved from http://krex.ksu.edu

\section{Published Version Information}

Citation: Fleming, S. D., \& Tsokos, G. C. (2006). Complement, natural antibodies, autoantibodies and tissue injury. Autoimmunity Reviews, 5(2), 89-92.

Copyright: Published by Elsevier B.V.

Digital Object Identifier (DOI): doi:10.1016/j.autrev.2005.09.006

Publisher's Link:

http://www.sciencedirect.com/science/article/pii/S156899720500159X

This item was retrieved from the K-State Research Exchange (K-REx), the institutional repository of Kansas State University. K-REx is available at http://krex.ksu.edu 


\section{Complement, Natural Antibodies, Autoantibodies and Tissue Injury}

Sherry D. Fleming ${ }^{\mathrm{a}}$ and George C. Tsokos ${ }^{\mathrm{b}, \mathrm{c}^{*}}$

a. Division of Biology, Kansas State University, Manhattan, KS 66506

b. Department of Cellular Injury, Walter Reed Army Institute of Research, Silver Spring, MD 20910

c. Department of Medicine, Uniformed Services University of the Health

Sciences, Bethesda, MD 20814

Corresponding Author:

Dr. George C. Tsokos

Walter Reed Army Institute of Research

Room 1A32, Building 503, Robert Grant Ave.

Silver Spring, MD 20910-7500

Tel: 301-319-9911

Fax: 301-319-9133

Email: gtsokos@usuhs.mil 


\begin{abstract}
Activation of the classical complement pathway represents an effector mechanism of intestinal ischemia/reperfusion injury. Mice deficient in complement receptors 1 and 2 fail to produce a component of the natural antibody repertoire that binds to ischemiaconditioned tissues and activate complement. In contrast, mice prone to autoimmunity display accelerated and enhanced tissue injury that results from the binding of autoantibodies to injured tissues. Our experiments demonstrate that naturally occurring antibodies and autoantibodies mediate tissue injury only after an organ has been subjected to a stressor such as ischemia.
\end{abstract}

Key Words: Natural antibodies, tissue injury, autoantibodies, complement activation 
Take-Home messages:

- Complement inhibitors attenuate mesenteric ischemia/reperfusion induced tissue damage.

- Classical complement pathway activation mediates a significant portion of mesenteric ischemia/reperfusion-induced tissue damage.

- Natural antibody repertoire contains antibodies that recognize ischemiaconditioned tissues, activate complement and cause tissue damage.

- Autoantibodies that recognize negatively charged phospholipids, DNA and histones bind to ischemia-conditioned tissues, activate complement and confer tissue damage.

\section{Introduction}

Tissue injury due to ischemia and subsequent reperfusion events is a common pathology that occurs in multiple clinical conditions. Organ ischemia induces immediate cellular injury that is significantly magnified by the return of blood flow and can lead to a systemic inflammatory response that damages remote organs as well. Due to the sensitivity of the mucosal surfaces, ischemia/reperfusion (I/R)-induced injury is exceptionally prominent in the intestine and frequently is followed by liver and lung [damage.

Mesenteric I/R- induced mucosal tissue injury is mediated by at least two components, neutrophil infiltration and complement activation. Initial studies showed protection from I/R-induced injury after neutrophil depletion [Hernandez, 1987 \#107; Simpson, 1993 \#127]. The involvement of complement activation in the mucosal damage was shown by the lack of damage in complement deficient mice (C3 or C4-/-) or 
after treatment with cobra venom factor that depletes C3 (1). Treatment with soluble Crry-Ig allowed neutrophil infiltration without significant tissue damage indicating that the presence of neutrophils is not sufficient for tissue damage (2). These studies also showed complement activation is critical to the induction of local mucosal damage and resulted in decreased systemic neutrophil activation as well (2). Inflammatory mediators of the complement pathway, such as the anaphylotoxin C5a, are known to be required for damage to remote organs including the lungs in response to mesenteric IR $(3,4)$.

\section{Complement in Tissue Injury}

The exact mechanism of complement activation during intestinal IR remains unclear as there is evidence that more than one complement pathway (classical, alternative or lectin) may become activated and enhance tissue injury $(1,5,6)$. However, two observations have strongly implicated the classical pathway in this process. The first is that intestinal IR injury is significantly decreased in $R A G-1-/-$ mice, and reconstitution of these Ig deficient mice with purified IgM natural antibody to normal levels restores IRinduced injury (1). The second is that mice with normal levels of natural antibody, but in which the gene encoding complement C4 is inactivated (C4-/-), are protected from injury (1). From these and other findings, it has been proposed that natural antibodies bind to neo-antigen(s) revealed on the surface membrane of cells subjected to ischemia

and subsequently activate complement by recruiting C1 and then cleaving C4 (1). This is followed by the generation of complement C3 and C5 activation fragments with ensuing increases in adhesion molecule expression and release of a cascade of inflammatory mediators, including leukotriene B4 and others $(2,6,7)$. 
The complement system may be important not only in the effector phases of tissue injury, as discussed above, but also in the development of a pathogenic subset of natural antibodies that recognize neo-antigens on ischemic tissue and then initiate intestinal IR injury. Complement receptor type 2 (CR2/CD21) is an important membrane receptor that greatly enhances B cell receptor (BCR) mediated activation by binding complement iC3b/C3d-decorated antigens and engaging the BCR/CR2/CD19/CD81 signaling complex (8). This recognition mechanism lowers the threshold for activation of B cells (9). In mice, CR2 is encoded along with the larger complement receptor type 1 (CR1) by the Cr2 gene, which produces both proteins through alternative splicing of a common mRNA $(10,11)$. CR2-/- mice demonstrate a substantial defect in the generation of IgG switched isotype responses $(12,13)$ as well as impaired B cell memory following immunization with T-dependent antigens $(13,14)$. To determine if CR2 plays a role in mesenteric IR, Cr2-/- mice were subjected to intestinal IR injury and were shown to be protected from the induction of tissue injury (6). Because the levels of complement molecules and complement activation are normal in Cr2-/- mice, other factors were considered to be responsible for this protection.

The defect was shown to lie in an altered repertoire of natural antibodies because infusion of IgM and IgG purified from the serum of wild type C57BL/6 mice in to Cr2-/mice prior to the ischemic phase resulted in reconstitution of the IR-induced injury (6). Of interest, transferred IgM and IgG each contributed to different aspects of tissue injury but together allowed the development of a complete injury phenotype (6). These findings demonstrated a previously unrecognized role for complement receptors in the 
development within the natural antibody repertoire of a tissue injury-inducing subset of antibodies.

\section{Autoantibodies in Tissue Injury}

The specific antibodies involved in I/R injury and the composition of the target antigen, to which recognition is lacking in Cr2-/- mice, are unknown. Since antiphospholipid antibodies have been shown to mediate fetal growth retardation and loss when injected in to pregnant mice $(15,16)$, experiments were performed to determine whether anti-phospholipid antibodies can also reconstitute I/R injury and represent members of the injury-inducing repertoire that is missing in $\mathrm{Cr} 2-/-$ mice. Both murine and human monoclonal and polyclonal antibodies against negatively-charged phospholipids can reconstitute mesenteric I/R-induced intestinal and lung tissue damage in $\mathrm{Cr} 2-/-$ mice (17). As indicated in Table 1, antibodies against $\beta 2$ glycoprotein I also restore local and remote tissue damage in the $\mathrm{Cr} 2-/-$ mice. Unlike $\mathrm{Cr} 2-/-$ mice, reconstitution of I/R tissue damage in the IR injury-resistant Rag-1-/- mouse required the infusion of both anti- $\beta 2$ glycoprotein I and anti-phospholipid antibody ((17) and Table 1). Therefore, anti-phospholipid antibodies can bind to tissues subjected to I/R insult and mediate tissue damage.

Autoantibodies have affinity and self-antigen recognition pattern similar to natural antibodies. Therefore, it is likely that autoimmunity prone mice expressing high titers of autoantibodies should have enhanced I/R-induced injury. The MRL/lpr mouse

develops clinical and serologic features similar to human systemic lupus erythematosus. The production of autoantibodies with multiple specificities including ssDNA, dsDNA, 
Sm, chromatin, RNA protein complexes and phospholipids typifies the disease (18). The C57BL/6-lpr/lpr (B6.MRL/lpr) mouse shows lymphadenopathy and autoimmunity although the levels of certain autoantibodies are lower than those in the MRLlpr/lpr mouse $(19,20)$. It was hypothesized that autoantibodies present in the sera of mice with systemic autoimmunity should initiate I/R-induced organ injury in a fashion similar to natural antibodies. This hypothesis predicted that autoimmunity-prone mice should display enhanced and accelerated I/R-induced intestinal damage and that infusion of autoimmune sera into I/R-resistant $\operatorname{Rag}-1^{-/}$mice should restore organ damage. Indeed, five-month-old B6.MRL/lpr mice displayed accelerated and enhanced intestinal I/Rinduced damage compared to two-month-old B6.MRL/lpr and age-matched C57Bl/6 mice (21). Similarly, older autoimmune mice had accelerated remote organ (lung) damage. Infusion of serum IgG derived from five-month but not two-month-old B6.MRL/lpr into I/R resistant $\operatorname{Rag}-1^{-/-}$mice rendered them susceptible to local and remote IR-induced organ injury (21). Injection of monoclonal IgG anti-DNA and antihistone antibodies in to Rag-1-/- mice effectively reconstituted tissue injury (21). These data show that like natural antibodies, autoantibodies, such as anti-dsDNA and antihistone antibodies, can instigate I/R injury and suggest that they are involved in the development of tissue damage in patients with systemic lupus erythematosus.

The fact that natural antibodies and various autoantibodies mediate the intestinal ischemia reperfusion injury should not be generalized to other target organ injuries. The kidneys of RAG-/- mice are not resistant to IR injury implying that neither immunoglobulin nor mature T cells are relevant in this injury (22). At this point more 
information is needed on various target organ models of tissue injury to acquire a complete picture of the involved mechanisms.

Based on the above information we propose that stress or injury alters the lipid membrane of cells such that certain antibodies found in the natural antibody repertoire and autoantibodies bind the cell surface and activate the complement cascade (Fig. 1). The ensuing complement activation leads two a two-pronged response by inducing direct cell lysis via membrane attack complex formation and inflammatory cell recruitment via the anaphylotoxins. Additional local and remote organ damage occurs as a result of complement activation. The production of antibodies that bind to ischemia-conditioned tissues require the presence of CR2 on the surface of B cells enabling the binding of antigen-C3dg complexes and the crosslinking the B cell receptor and CR2.

The opinions contained herein are the private ones of the authors and are not to be constructed as official policy or reflecting the views of the Department of Defense. 


\section{Figure legend}

Figure 1. Proposed model of antibody mediated tissue injury. Natural antibodies able to recognize ischemia or stress altered cells are produced by B cells in response to antigen-C3dg complexes crosslinking the B cell receptor and CR2 (1).

Autoantibodies with specificities against phospholipids, dsDNA and histones alos bind stressed cells (2). Complement activation induces a bi-directional response by inducing direct cell lysis via membrane attack complex formation and inflammatory cell recruitment via the anaphylotoxins (3). Additional damage occurs as a result of complement activation. 
Table1: Antibodies injected prior to IR treatment.

\begin{tabular}{|l|l|l|l|l|}
\hline $\begin{array}{l}\text { Antibody } \\
\text { Clone }\end{array}$ & Specificity & Isotype & $\begin{array}{l}\text { Damage in } \\
\text { Cr2-/- }\end{array}$ & $\begin{array}{l}\text { Damage in } \\
\text { Rag-1-/- }\end{array}$ \\
\hline FA3 & Phospholipids & IgG3 & Yes & No \\
\hline FB1 & Phospholipids & IgG2b & No & No \\
\hline FC1 & $\beta 2$ GPI & IgG1 & Yes & No \\
\hline FC2 & $\beta 2$ GPI & IgG1 & No & No \\
\hline PL9-7 & Histone & IgG3 & Yes & Yes \\
\hline PL9-11 & DNA & IgG3 & Yes & Yes \\
\hline
\end{tabular}




\section{References}

1. Williams, J. P., T. T. V. Pechet, M. R. Weiser, R. Reid, L. Kobzik, F. D. Moore, M. C. Carroll, and H. B. Hechtman. 1999. Intestinal reperfusion injury is mediated by IgM and complement. J. Appl. Physiol. 86:938-942

2. $\quad$ Rehrig, S., S. D. Fleming, J. Anderson, J. M. Guthridge, J. Rakstang, C. E. McQueen, V. M. Holers, G. C. Tsokos, and T. Shea-Donohue. 2001. Complement inhibitor, complement receptor 1-related gene/protein y-Ig attenuates intestinal damage after the onset of mesenteric ischemia/reperfusion injury in mice. $J$. Immunol. 167:5921-5927

3. Fleming, S. D., J. Anderson, F. Wilson, T. Shea-Donohue, and G. C. Tsokos. 2003. C5 is required for CD49d expression on neutrophils and VCAM expression on vascular endothelial cells following mesenteric ischemia/reperfusion. Clin. Immunol. 106:55-64

4. $\quad$ Fleming, S. D., D. Mastellos, G. Karpel-Massler, T. Shea-Donohue, J. D. Lambris, and G. C. Tsokos. 2003. C5a causes limited, polymorphonuclear cellindependent, mesenteric ischemia/reperfusion-induced injury. Clin. Immunol. 108:263-273

5. Stahl, G. L., Y. Xu, L. Hao, M. Miller, J. A. Buras, M. Fung, and H. Zhao. 2003. Role for the alternate complement pathway in ischemia/reperfusion injury. Am. J. Pathol. 162:449-455

6. Fleming, S. D., T. Shea-Donohue, J. M. Guthridge, L. Kulik, T. J. Waldschmidt, M. G. Gipson, G. C. Tsokos, and V. M. Holers. 2002. Mice deficient in complement receptors 1 and 2 lack a tissue injury-inducing subset of the natural antibody repertoire. J. Immunol. 169:2126-2133

7. Eror, A. T., A. Stojadinovic, B. W. Starnes, S. C. Makrides, G. C. Tsokos, and T. Shea-Donohue. 1999. Anti-inflammatory effects of soluble complement receptor type 1 promote rapid recovery of ischemia/reperfusion injury in rat small intestine. Clin. Immunol. 90:266-275

8. Tsokos, G. C., J. D. Lambris, F. D. Finkelman, E. D. Anastassiou, and C. H. June. 1990. Monovalent ligands of complement receptor 2 inhibit whereas polyvalent ligands enhance anti-Ig-induced human B cell intracytoplasmic free calcium concentration. J. Immunol. 144:1640-1645

9. Fearon, D. T., and R. H. Carter. 1995. The CD19/CR2/TAPA-1 complex of B lymphocytes: linking natural to acquired immunity. Annu Rev Immunol 13:127

10. Kurtz, C. B., E. O'Toole, S. M. Christensen, and J. H. Weis. 1990. The murine complement receptor gene family. IV. Alternative splicing of $\mathrm{Cr} 2$ gene transcripts predicts two distinct gene products that share homologous domains with both human CR2 and CR1. J. Immunol. 144:3581-3591

11. Molina, H., T. Kinoshita, K. Inoue, J.-C. Carel, and V. M. Holers. 1990. A molecular and immunochemical characterization of mouse CR2: Evidence for a single gene model of mouse Complement Receptors 1 and 2. J. Immunol. 145:2974-2983

12. Ahearn, J. M., M. B. Fischer, D. Croix, S. Goerg, M. Ma, J. Xia, X. Zhou, R. G. Howard, T. L. Rothstein, and M. C. Carroll. 1996. Disruption of the Cr2 locus 
results in a reduction in B-1a cells and in an impaired B cell response to Tdependent antigen. Immunity 4:251-262

13. Molina, H., V. M. Holers, B. Li, Y. Fung, S. Mariathasan, J. Goellner, J. StraussSchoenberger, R. W. Karr, and D. D. Chaplin. 1996. Markedly impaired humoral immune response in mice deficient in complement receptors 1 and 2. Immunology 93:3357-3361

14. Croix, D. A., J. M. Ahearn, A. M. Rosengard, S. Han, G. Kelsoe, M. Ma, and M. C. Carroll. 1996. Antibody response to a T-dependent antigen requires B cell expression of complement receptors. J. Exp. Med. 183:1857-1864

15. Holers, V. M., G. Girardi, L. Mo, J. M. Guthridge, H. Molina, S. S. Pierangeli, R. Espinola, L. E. Xiaowei, D. Mao, C. G. Vialpando, and J. E. Salmon. 2002. Complement C3 activation is required for antiphospholipid antibody-induced fetal loss. J. Exp. Med. 195:211-220

16. Salmon, J. E., G. Girardi, and V. M. Holers. 2002. Complement activation as a mediator of antiphospholipid antibody induced pregnancy loss and thrombosis. Annals of the Rheumatic Diseases 61(Supp II):ii46-ii50

17. Fleming, S. D., R. P. Egan, C. Chai, G. Girardi, V. M. Holers, J. Salmon, M. Monestier, and G. C. Tsokos. 2004. Anti-phospholipid antibodies restore mesenteric ischemia/reperfusion-induced injury in complement receptor 2/complement receptor 1-deficient mice. J. Immunol. 173:7055-7061

18. Theofilopoulos, A. N. Murine models of lupus. In Systemic Lupus Erythematosus, Second edition ed. R. G. Lahita, ed. Churchill Livingstone, New York. 121-185.

19. Eisenberg, R. A., S. Y. Craven, C. L. Fisher, S. C. Morris, R. Rapoport, D. S. Pisetsky, and P. L. Cohen. 1989. The genetics of autoantibody production in MRL/lpr lupus mice. Clinical and Experimental Rheumatology 7 Suppl 3:S35-40

20. Warren, R. W., S. A. Caster, J. B. Roths, E. D. Murphy, and D. S. Pisetsky. 1984. The influence of the lpr gene on B cell activation: differential antibody expression in lpr congenic mouse strains. Clinical Immunology and Immunopathology 31:6577

21. Fleming, S. D., M. Monestier, and G. C. Tsokos. 2004. Accelerated ischemia/reperfusion-induced injury in autoimmunity-prone mice. J. Immunol. 173:4230 - 4235

22. Burne, M. J., F. Daniels, A. El Ghandour, S. Mauiyyedi, R. B. Colvin, M. P. O'Donnell, and H. Rabb. 2001. Identification of the CD4(+) T cell as a major pathogenic factor in ischemic acute renal failure. J. Clin. Invest. 108:1283-1290 


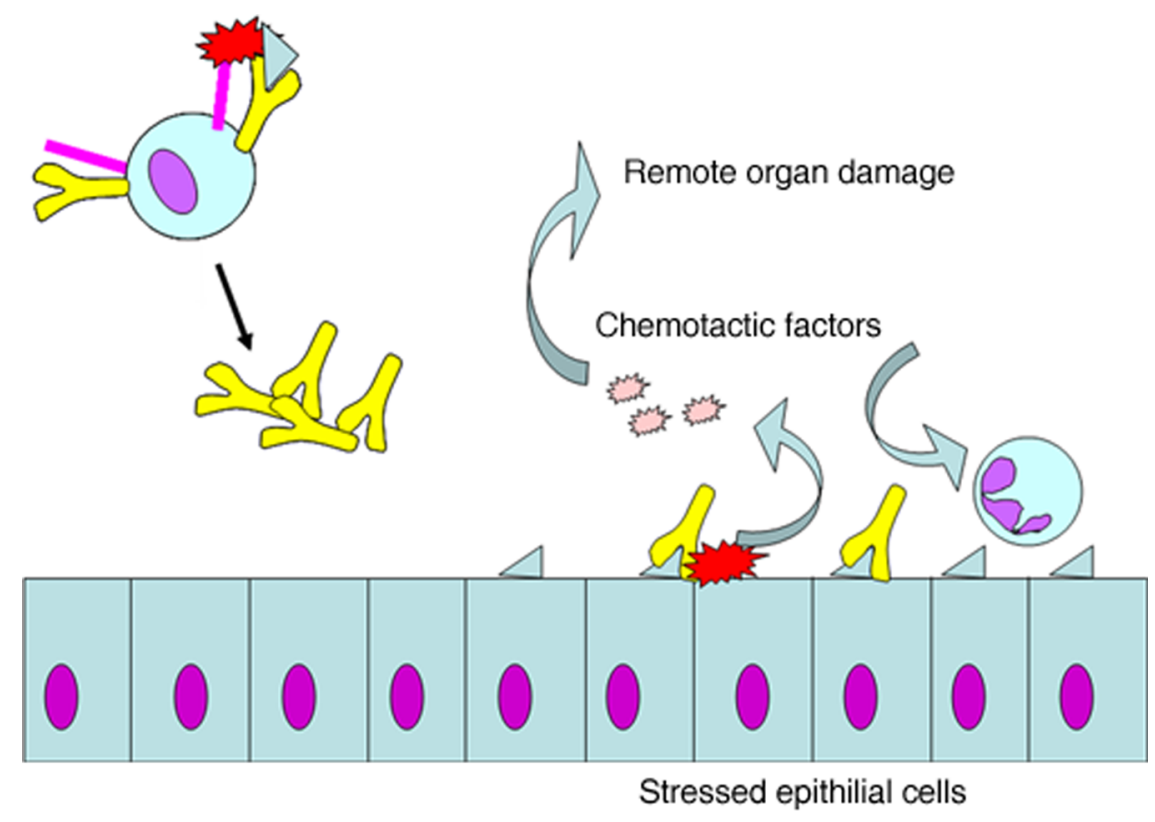

